\title{
Discussion on the Curriculum Reform of Electromechanical Drive Control
}

\author{
Wang $\mathrm{Yao}^{1}$, $\mathrm{Li} \mathrm{Hongzhou}^{1}, \mathrm{Xu} \mathrm{Miao}{ }^{2}$, Bai Yan ${ }^{3}$ \\ ${ }^{1}$ School of Mechanical Engineering, Beihua University, Jilin, China \\ ${ }^{2}$ School of automotive and architectural engineering, Beihua University, Jilin, China \\ ${ }^{3}$ Engineering Training Center, Beihua University, Jilin, China
}

Keywords: Electromechanical drive control, teaching reform, teaching content, teaching method

\begin{abstract}
The curriculum of electromechanical drive control has the characteristics of theory and practice. This paper analyzes the background of curriculum reform, and puts forward the reform measures and concrete measures from the aspects of curriculum system, teaching content, teaching material compiling and practice links.
\end{abstract}

\section{Introduction}

The curriculum of electromechanical drive control is a required course for undergraduates majoring in machine design and manufacturing and its automation. Because of the power transmission control device and mechanical equipment is an indivisible whole, through the study of this course, students should be able to understand the working principle, characteristics, application and selection of the master commonly used method of electromechanical drive control; master the common drive motor, servo motor, low-voltage electrical appliances and thyristor; the open loop and closed loop control system of the working principle, characteristics, properties and application places; master relay contactor control circuit and the programmable controller PLC system control principle, design method and typical application examples of control; the latest control technology in mechanical devices.

\section{The Background of Curriculum Reform}

Taking the curriculum of electromechanical drive control in our institute as an example, the main content of the course is divided into two parts years ago. Namely, the relay contactor control part and the programmable controller part. The relay contactor part teaching common low-voltage electrical components, such as fuses, circuit breakers, contactors, relays, main command appliance and typical control links such as asynchronous motor start, adjust speed and braking etc.. The programmable controller part mainly teaches the PLC working principle, main structure, internal soft component and the OMRON series PLC's instruction and so on. Previous teaching practice has proved that the teaching method of classification teaching is not only difficult to arouse the interest of these students, but their comprehensive practice ability has not improved significantly. All these influence the teaching effect, so we must carry on the reform of the teaching mode. The image thinking is the logical thinking of good students, if using the conventional machine tools and CNC machine tool as the carrier, using the " string line" to guide students to complete the whole process of teaching, and improve students' comprehensive ability and interest in learning.

\section{Curriculum System Reform}

We set up a new curriculum system. According to the development of science and its inherent laws, the drive motor, electric motor, electric drive control, relay contactor control, programmable controller, power electronics, DC, AC, stepping motor servo system and electric control content combined organically. The electric control knowledge, electromechanical integration technology required are 
concentrated in this course. It is not only to avoid unnecessary duplication, strengthen the systematicness and theory with practice. Enable students to have a comprehensive and systematic understanding of the low voltage control part of electrical control technology in mechatronic products.

\section{Teaching Content Reform}

In addition to the original content, the traditional production machinery control system, common control motor introduction, frequency conversion technology and CNC machine tool control system have been added.

Relay Contactor Control System. Teach traditional and advanced low voltage electrical components, including knives, switches, fuses, circuit breakers, electromagnetic actuators, contactors, relays, and various master electrical appliances. Teaching three-phase asynchronous motor starting, braking, adjust speed and stroke control circuit and its design method.

Control System of Traditional Production Machinery. General lathe control system; surface grinding machine control system; radial drilling machine control system; universal horizontal milling machine control system; electric hoist control system.

Programmable Controller Overview. Teach the generation, definition, function, characteristic and composition of programmable controller, working principle of programmable controller, programming language, internal soft parts and addressing mode, etc..

Programmable Controller Control Instruction. Teaching programmable controller commonly used control instructions; PLC ladder diagram design methods, including experience method, timing method, sequence control instructions.

Commonly Used Control Motors. The working principle and drive mode of stepping motor, DC servo motor and AC servo motor are introduced. Frequency conversion technology.

CNC Machine Tools Electrical Control System. This paper introduces the basic structure and connection of machine tool numerical control system, the debugging of basic parameter of NC system, and the example of NC machine tool.

\section{Teaching Material Reform}

With the development of PLC technology and network control technology, the content of electrical control system is constantly updated. To this end, we have prepared the "mechanical and electrical transmission control" teaching materials, the new teaching materials highlight the following features:

(1) To retain the basic principles commonly used low-voltage electrical appliances, electrical control circuit and basic control link, the typical production machinery and electrical control circuit, electrical control circuit design of the basic part, on behalf of the factory and the commonly used new technology development direction of the programmable controller principle and application content.

(2) Typical production machinery, electrical control circuit analysis, adding CNC machine tools of electrical control content: CNC lathe electrical control, line analysis and CNC milling machine electrical control, circuit analysis.

(3) For the development of new and high technology, add a chapter to describe the principle and application of built-in PLC in CNC system.

\section{Practice Reform}

The reform of practice can be divided into three levels.

(1)Validation experiments, including recognition, commonly used low voltage electrical components structure of motor structure understanding, understanding, structure dynamic programming controller control circuit, control circuit, starting control circuit, reversing control circuit, brake control 
circuit and PLC basic programming experiment, with the expected results, can make students deepen the understanding of curriculum content, training of practical ability;

(2)Work as an electrician engineering practice in the engineering training center or factory to further train the site wiring and troubleshooting capability required by the position;

(3)In modern teaching means using the programmable controller in the teaching of computer programming, program transmission and online debugging with PLC special communication software, and as much as possible to test operation results in the control object, is the innovation and design experiments. We basically do all the stages of the three levels of practical teaching continuously. The basic curriculum experiment, electrician engineering practice, production practice continued.

(4)In recent years, "3D printing" is research heat higher mechanical and electrical integration products. We can train the students and improve their learning interest combined with the 3D printing training room.

\section{Conclusion}

After several years of effort, the reform of the curriculum reform of electromechanical drive control has made some achievements, but there are still some problems worth considering and problems to be solved. Such as practical resources strained. We will continue our efforts in the reform of teaching content, at the same time, increase the self-made experimental equipment; extend the opening hours of laboratory; adding innovative experimental and designing project; vertical subject and horizontal subject guide students to participate in teaching. In the constant reform and practice, the curriculum reform of electromechanical drive control is regarded as a complete, advanced and practical feature as a provincial excellent curriculum.

\section{Acknowledgment}

The research is funded by the research project of education and teaching reform in Beihua University(Application research and practice of 3D printing technology in "project" teaching).

\section{Reference}

[1] Huang Wen,Li Shuzhen,Wu Hong. University students occupation ability training mode of core[J]. Journal of higher education finance, 2012 (3) :68-70.

[2] Xiao Yu. Enhancing the building of experimental teaching demonstration center to bring up the students’ innovation ability[J]. Research and exploration in laboratory, 2014 , 33 (7) :157-160.

[3] Zheng Hongwei,Zhang Yanrui,Ma Yuqiong,Li Shijie,Dai Shijie. Study and exploration of open laboratory with 3D printing laboratory based on innovation ability cultivation[J]. Experimental Technology and Management, 230 (11) :159-162.

[4] Xu Qiang,Feng Qian. Exploration of teaching reform of mechanical specialty under the scientific research direction[J]. China education innovation herald, 2009 (2) :194-194. 